\title{
Alfabetização sob a perspectiva da neurociência
}

\author{
Miriam da Silva Pinto ${ }^{1}$ \\ Dr. Fabiano de Abreu Agrela Rodrigues ${ }^{2}$ \\ deabreu.fabiano@gmail.com
}

\section{RESUMO}

O presente artigo tem como objetivo apresentar um estudo bibliográfico a respeito das contribuições da neurociência, em especial das ciências cognitivas, abordando a dinâmica do cérebro humano na aprendizagem da leitura, o fenômeno da neuroplasticidade vista sobre a ótica dos métodos de estudos científicos, as bases cognitivas da aprendizagem da leitura e os estágios iniciais dessa aprendizagem, a evidência da eficácia de alguns métodos de alfabetização, o método de ensino da leitura, a neurobiologia, além de algumas políticas de alfabetização brasileiras que se ancoram nessa perspectiva cientifica. $\mathrm{Na}$ tentativa de responder como o cérebro humano aprende a ler e como educadores podem reavaliar os métodos de ensino para conseguir resultados precisos e eficientes na aprendizagem da leitura, recorremos à pesquisa bibliográfica, cuja escolha se deu pela importância dos autores e dos grupos de pesquisadores no Brasil e de fora que construíram alguns materiais de estudo à respeito do tema destacando: ABREU (2020-2021), CAPOVILLA (2005), DEHAENE (2012), GARDNER (1996), GT:ALFABETIZAÇÃO INFANTIL: os novos caminhos relatório final (2007), GE: APRENDIZAGEM INFANTIL, Uma abordagem da Neurociência, da Academia Brasileira de Ciências (2011), PERRENOUD (2002), PNA (2019) dentre outros.

Palavras-chaves: neurociência e educação; aprendizado da leitura; métodos de ensino da leitura; políticas de alfabetização.

\footnotetext{
${ }^{1}$ Mestranda em Educação e Ciências pela World Christian University, Pedagoga pela UEG, Especialista em Métodos e Técnicas de Pesquisa (UNIVERSO), Neuropedagogia e Psicanálise (Fac. Ávila), Inclusão com ênfase em AEE (FABEC), Neuropsicopedagogia (Faculdade Metropolitana /SP) e Analista educacional pelo Departamento de Ensino e Aprendizagem da CEA/SME. E-mail: mdmisilva@ gmail.com. ${ }^{2} \mathrm{PhD}$, neurocientista, mestre em psicanálise, biólogo, historiador, antropólogo, com formações também em neuropsicologia, neurolinguística, neuroplasticidade, inteligência artificial, neurociência aplicada à aprendizagem, filosofia, jornalismo, programação em python e formação profissional em nutrição clínica Diretor do Centro de Pesquisas e Análises Heráclito; Chefe do Departamento de Ciências e Tecnologia da Logos University International e da City University; Membro da SFN - Society for Neuroscience, Membro Redilat.
} 


\title{
Literacy from the perspective of neuroscience
}

\begin{abstract}
This article has the purpose to introduce a bibliographic study about the contributions of neuroscience, especially the cognitive science, approaching the dynamics of human brain in reading learning, the neuroplasticity phenomenon seen under the methods of scientific studies, the cognitive foundations of reading learning, the initial stages of this learning, the evidence of the effectiveness of some literacy methods, the method of reading teaching, the neurobiology and some literacy policies that are based on this scientific perspective. In an attempt to answer the question about how the human brain learn to read and how the educators can re-evaluate the teaching methods to get accurate and efficient results on reading learning, we used bibliographic research. The choices we made were based on the importance of the authors and the groups of Brazillian and Foreigner researchers who built some materials about this subject, especially: ABREU (2020-2021), CAPOVILLA (2005), DEHAENE (2012), GARDNER (1996), GT: ALFABETIZAÇÃO INFANTIL: os novos caminhos relatório final (2007), GE: APRENDIZAGEM INFANTIL, uma abordagem da Neurociência, da Academia Brasileira de Ciências (2011), PERRENOUD (2002), PNA (2019) and others.
\end{abstract}

Keywords: neuroscience and education.; reading learning; reading teaching methods; literacy policies.

Artículo recibido: 02 enero 2022 Aceptado para publicación: 28 enero 2022 Correspondencia: deabreu.fabiano@gmail.com Conflictos de Interés: Ninguna que declarar 


\section{INTRODUÇÃO}

O presente artigo propõe uma análise referente à aplicação das contribuições da neurociência na educação. A neurociência educacional, ciência de base para a pedagogia pode fundamentá-la empiricamente e não apenas as ciências sociais, mas as biológicas e comportamentais, diante do atual quadro da educação brasileira principalmente no que se refere à aprendizagem da leitura- como parte da escolarização e mesmo sendo um ramo científico sólido de estudos nos últimos 30 anos, está à margem nos debates das políticas educacionais brasileiras, pois a Ciência Cognitiva da Leitura apresenta um discurso na contramão da concepção de aprendizagem de leitura apresentada no país e, tal conhecimento científico é rejeitado muitas vezes por questões de ordem política e ideológica (GT: ALFABETIZAÇÃO INFANTIL: os novos caminhos relatório final, 2007,21).

Nosso cérebro é evidentemente capaz da aprendizagem, porém a aprendizagem da leitura diferentemente da aquisição da fala, é limitada. Em todos os lugares do mundo, em todas as culturas com suas diferentes linguagens escritas, a mesma região cerebral, com diferenças mínimas de milímetros, intervém para decodificar as palavras escritas, sejam elas em qualquer língua, pois a aprendizagem da leitura percorre sempre um circuito cerebral idêntico, no Brasil ou no Japão. Nosso cérebro não é uma tábula rasa onde se acumulam construções culturais: ele é um órgão estruturado que faz o novo com o velho. Em “A nova ciência da Mente”, GARDNER (1996) afirma que:

“Os cientistas cognitivos [...] procuram entender o que é conhecido e a pessoa que conhece - seu aparelho perceptivo, mecanismos de aprendizagem, memória e racionalidade. Eles investigam as fontes do conhecimento: de onde vem, como é armazenado e recuperado, como ele pode ser perdido. [...] adotam os mais recentes avanços científicos e tecnológicos de várias disciplinas". (p.18-19).

De acordo com $\mathbf{L D B}^{3}$ (Lei no 9394/96, art. 32, inciso I): “A formação básica do cidadão é o objetivo do ensino fundamental, mediante o desenvolvimento da capacidade de aprender, tendo por meios básicos o pleno domínio da leitura, da escrita e do cálculo", bem como o exposto nas Metas 5 e 9 do $\mathbf{P N E}^{4}$ (2014) respectivamente: Alfabetizar todas

\footnotetext{
${ }^{3}$ LDB Lei de diretrizes e bases da Educação.

${ }^{4}$ PNE - Plano Nacional de Educação
} 
as crianças até o fim do $3^{\circ}$ ano do EF e reduzir a taxa de analfabetismo funcional (condição daquele que possui habilidades limitadas de leitura e compreensão de texto) em 50\%. Erradicar o analfabetismo absoluto (condição daquele que não sabe ler nem escrever) até 2024 serve como base de análise se os objetivos sobre os processos e resultados da alfabetização no Brasil foram ou não satisfatórios. A BNCC $\mathbf{B}^{\mathbf{5}}$ (2017) que propõe conteúdos mínimos para cada etapa da escolarização, espera-se que a criança seja alfabetizada no $1^{\circ}$ e $2^{\circ}$ ano do ensino fundamental, processo que será complementado por outro no $3^{\circ}$ ano, denominado de "ortografização".

Porém, analisando estatisticamente a atual realidade brasileira em alfabetização, a $\mathbf{A N A}^{\mathbf{6}}$ de 2016, que abarcou mais de 2 milhões de alunos concluintes do $3^{\circ}$ Ano de EF, constatou que: $54,73 \%$ dos alunos apresentaram desempenho insuficiente no exame de proficiência em leitura e 400 mil desses ficaram em nível 1 dessa escala; 33,95 estavam em níveis insuficientes de escrita (1, 2 e 3) e 680 mil não conseguem escrever "palavras alfabeticamente" ou as escrevem com desvios ortográficos; (INEP, 2016). Comprova-se, que a trajetória escolar desses estudantes fica comprometida, refletindo em reprovação, distorção idade-série, abandono e evasão, e perda da capacidade de compreensão de textos pelo empobrecimento do repertório linguístico.

\section{FUNDAMENTAÇÃO TEÓRICA}

\subsection{Neurociência E Aprendizagem}

As pesquisas neurocientíficas em leitura, dos últimos 30 anos, adquiriram um status científico incontestável pelo uso de metodologias experimentais (laboratório e campo) fortalecendo a qualidade dos dados e análises, baseando-se nos testes de hipóteses isolando a variável em grupos experimentais e de controle, com procedimentos bem estabelecidos e reconhecidos pela comunidade científica internacional, rompendo com o mundo da especulação e amadorismo para se situar dentro do rigor científico, assim como nas pesquisas em Física ou em Biologia.

Os métodos de estudo das (Neuro)Ciências Cognitivas da Leitura se fundaram no cognitivismo computacional, em que o cérebro humano é metaforicamente entendido como um dispositivo, que processa informações e emite respostas. $\mathrm{O}$ uso avançado das tecnologias computacionais e seus estudos funcionais como tomografia de emissão de

\footnotetext{
5 BNCC - Base Nacional Comum Curricular

${ }^{6}$ ANA - Avaliação Nacional de Alfabetização
} 
pósitrons (PET ou TEP), da ressonância magnética funcional (RMF ou IRMf) e a Magnetoencefalografia (MEG) verificou-se a neuroplasticidade cerebral na aprendizagem, o desenvolvimento das estruturas encefálicas, concluindo que a capacidade da leitura está relacionada a regiões específicas do cérebro que precisam ser profundamente estimuladas e ativadas, levando em consideração os neurotransmissores envolvidos. Possibilitou localizar distúrbios de aprendizagem, mensurar a atividade do cérebro com base em mudanças respectivamente, no fluxo sanguíneo cerebral regional ou na oxigenação do sangue.

A apresentação de um estímulo ou um estado mental envolve a ativação neural em regiões cerebrais específicas, ativação por oxigenação ou fluxo sanguíneo. O neuroimageamento funcional é "uma técnica útil para identificar os sistemas neurais que dão suporte a processos cognitivos como a leitura” (SNOWLING \& HULME, 2013, 492). Cabe ao neurocientista interpretar o volume de informações captadas por esses instrumentos para entender melhor o fenômeno dentro de uma avaliação multimodal ou multidisciplinar e assim chegar à resposta científica.

O cérebro humano é capaz da Neuroplasticidade que é " $a$ adaptação funcional $e$ estrutural que minimiza ou reverte os efeitos das alterações estruturais (lesionais) ou funcionais do sistema nervoso e que também permite a aquisição do conhecimento". (ACADEMIA BRASILEIRA DE CIÊNCIAS, 2011, p. 48). Na Reciclagem neuronal em DEHAENE (2012), oposta ao relativismo cultural, as invenções culturais, como a aprendizagem da leitura se insere na margem da neuroplasticidade, em que a habilidade da leitura se utiliza das predisposições cerebrais já presentes no indivíduo.

Na Neurociência Cognitiva, a aprendizagem humana pode ser compreendida como o processamento e a elaboração das informações vindas do aspecto perceptivo do cérebro e à sua capacidade de associar tais informações aos significados, interpretando-os. Adquirir novas informações e retê-las na memória é aprendizagem, necessitando apenas que determinados neurônios sejam estimulados. No processo de aprendizagem da leitura, a neuroplasticidade em termos orgânicos, ocorre pelo aumento dos corpos neuronais, deixando os dendritos mais robustos, aumentando a potência sináptica.

Os estímulos sensoriais captados pelo neurônio que funciona como um interruptor que deixa ou não passar a corrente elétrica, de modo reconfigurável. O corpo do neurônio é a fonte de alimentação e absorção do oxigênio. Os dendritos recebem informações de 
outros neurônios e se essas preencherem determinadas condições, o neurônio dispara um pulso elétrico pelo axônio (corpo) que quando tais pulsos chegam à extremidade distribuise por mais ramificações que se conectam a outros neurônios. As informações das conexões sinápticas são transmitidas pelos Neurotransmissores de forma química.

Porém, o neurônio só dispara o pulso elétrico se as excitações provenientes dos vários neurônios pré-sinápticos que atingem os pós-sinápticos, atingirem ou superarem certa intensidade limite, do contrário ele fica quieto. Por meio de treinamento, uma rede neural pode, sem alterar as ligações físicas entre os neurônios, modificar seu comportamento aprendendo a executar outras tarefas (isso é a neuroplasticidade), mudando a "força" da sinapse a partir da modificação da quantidade de neurotransmissores que atravessam a sinapse quando ela é excitada. É justamente nas sinapses de dezenas de milhões de neurônios que se dá o mecanismo do pensamento e a aprendizagem da leitura é o resultado da neuroplasticidade.

Figura 1 - Estrutura de um neurônio

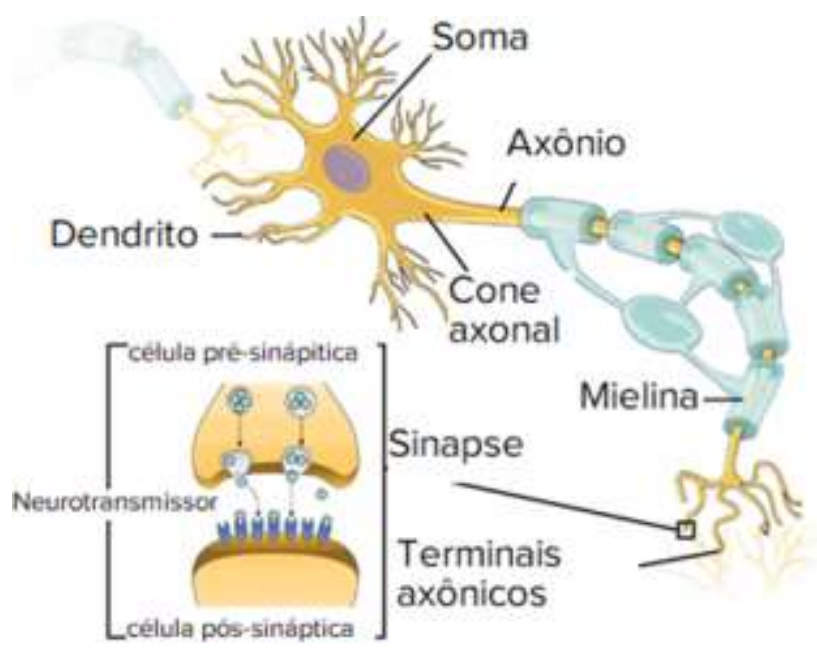

Em uma das extremidades do corpo celular estão os dendritos. Projetando-se da outra extremidade do corpo celular está o axônio. O axônio é envolvido por mielina, que constitui uma bainha em volta de algumas seções. Em sua extremidade mais distante do corpo celular, o axônio se ramifica em muitos terminais axônicos. Cada um forma uma sinapse com um dendrito ou corpo celular de outro neurônio. Há um espaço entre os dois neurônios. A comunicação se dá pela liberação de neurotransmissores nesse espaço.

Fonte: Imagem modificada de "Neurons and glial cells: Figure 2" and "Synapse," por OpenStax College, Biology (CC BY 3.0). 
A capacidade de aprender é ampla, ilimitada e o cérebro pode renovar a si mesmo, e a plasticidade é importante, pois, as áreas cerebrais de uma determinada função podem assumir outras funções quando necessárias, apresentando interdisciplinaridade cerebral (p.35) que é quando o conhecimento de uma área é aproveitado em outra área: “ $A$ aprendizagem se dá pela criação de novas memórias e pela ampliação das redes neuronais que armazenam o que já foi trabalhado, por meio das aprendizagens de conceitos e das metodologias que irão formar ou ampliar estas memórias”. (RELVAS, 2007, p. 35)

Todas as áreas cerebrais estão envolvidas na aprendizagem inclusive a emoção, e, neurobiologicamente, ocorre alteração ou crescimento das células neurais quando os estímulos potencialmente fortes são repassados de uma célula à outra. RELVAS (2009) descreve esse processo:

“[...] existe uma organização bioquímica envolvida, denominada de neurotransmissor do tipo GLUTAMATO. Os receptores destes estímulos são chamados de NMDA (agem nos canais bloqueados) $e$ AMPA (mediam o que vem das membranas pré-sinápticas). Quando o estímulo é muito forte, os estímulos vão para os NMDA. Aí, há passagem de íons de Ca (cálcio). Todo esse processo pode durar horas ou dias e interfere nos processos de memória e aprendizagem”. (p.36)

Para que a criança aprenda é necessário que ocorram modificações permanentes nas sinapses das redes neurais de cada memória e, para ativação da memória é necessária a reativação de redes sinápticas de cada memória armazenada e como seu sistema nervoso é mais plástico do que o de um adulto, a estimulação precoce e correta pode aumentar o potencial da aprendizagem no contexto escolar, principalmente no desenvolvimento das múltiplas inteligências de que fala Howard Gardner (1995). Assim, a memória é a base do aprendizado, pois, quanto mais conexões neurais, mais memória e mais capacidade de planejamento, de abstração, de julgamento e de atenção.

RELVAS (2007) descreve o caminho percorrido pelos estímulos no sistema nervoso central (SNC) da seguinte forma: o córtex cerebral, no lobo temporal recebe, integra e organiza os estímulos auditivos; no lobo occipital, o córtex recebe, integra e organiza os estímulos visuais; nas áreas temporal e occipital se ligam às áreas do lobo frontal responsável pela articulação das palavras; a área parietotemporoccipital é responsável 
pela integração do conhecimento e as áreas pré-frontais pela integração da prática, tudo pelo viés do afeto e das condições cognitivas de cada indivíduo (p.92). As células nervosas crescem e se modificam em respostas às experiências e "os estímulos externos que causam as reações emocionais e o significado que se dá a essas reações são a maneira pela qual o humano expressa o resultado da aprendizagem”. (p.192).

O cérebro ora se comporta utilizando as redes neurais já configuradas, ou o processamento permanece desligado reconfigurando sinapses durante o sono. Esse “configurar e reconfigurar" que corresponde à aprendizagem obedecem também ao rítmo circadiano. (PIAZZI, 2014, p. 95) Todo esse processo, dentro da sinaptogênese, em que a aprendizagem decorrente da plasticidade neuronal acontece, altera química, anatômica e fisiologicamente o cérebro, ao exigir alterações nas redes neurais, a partir de situações que inibem ou estimulem o surgimento de novas sinapses, mediante a liberação de neurotransmissores (MORA, 2004).

Os neurotransmissores desempenham papel preponderante no processo de aprendizagem, na medida em que contribuem para a criação de hábitos de leitura, de formação de memória, na formatação na criança da cultura de curiosidade. Eles são responsáveis por transmitir as informações entre as pré-sinapses e pós-sinapses. Nesse processo de aprendizagem, o GABA, por exemplo é indicado como ativador do metabolismo cerebral em situações de déficits de memória, dificuldade de atenção e memorização dos conteúdos. A Serotonina traz contribuições para a motivação na aprendizagem, melhorando o humor, regulando o sono comprovando que o sono interfere na aprendizagem, e suas alterações provocam desatenção. A noradrenalina como principal neurotransmissor do sistema nervoso simpático periférico é objeto de estudo no que se refere ao sono, aprendizagem e atenção, funções executivas e ao desejo de aprender (ABREU, 2020, p. 4-5). A dopamina conhecida como neuro da recompensa, sintetizado por meio da tirosina e acumulado nas vesículas sinápticas nos terminais axônicos está ligado à Motivação, Movimento e Intelectualidade. Ela é que promove a repetição de ações prazerosas sendo necessária à formação do hábito da leitura apesar de ser viciante ${ }^{7}$.

\footnotetext{
${ }^{7}$ Sobre a capacidade viciante da dopamina, recomenda-se a leitura de A internet deixa as pessoas menos inteligentes? Saiba de que modo usá-la publicada em 31/03/2021 < https://www.tecmundo.com.br/internet/214788-internet-deixa-pessoas-inteligentes-saiba-usa.htm> e Alunos distraídos e sem memória: como o vício em dopamina pode impactar a educação? Publicado em 21/06/21 < https://saopauloparacriancas.com.br/alunos-distraidos-sem-memoria/>
} 
Alterações dopaminérgicas afetam a formação da personalidade no que se refere à falta de atenção tão necessária à aprendizagem e às vezes apresenta-se em forma de TDH.

Figura 2 - Trabalho dos neurotransmissores



Fonte: https://www.neurometria.com.br

Aprender a ler consiste em acessar, através da visão, as áreas cerebrais da linguagem falada nas interações e cultura da curiosidade. E apresentar dificuldades nessa aprendizagem, significa a quantidade de reciclagem neuronal necessária. Assim os exames com capacidade de avaliação de alterações hemodinâmicas e metabólicas com a RMf e o PET permitem uma localização muito precisa das regiões cerebrais envolvidas no ato da leitura. A neurociência traz das bases científicas, a mudança didática, curricular e estrutural da escola e da aprendizagem.

\subsection{Aprendizagem da Leitura}

O cérebro da criança é extremamente estruturado, nossas redes cerebrais são capacitadas para processamentos complexos graças à reciclagem neuronal (ou neuroplasticidade), pela qual os neurônios são capazes de aprender, através da reorientação dos sistemas cerebrais para símbolos novos, pertencentes a cada cultura. $\mathrm{O}$ bebê, mesmo ainda sem a linguagem oral desenvolvida, apresenta uma curiosidade natural, pois, tudo que ele observa é novo, mesmo sem falar ele demonstra tal curiosidade. Á medida que ampliar a oralidade entra na fase dos "por quês". Daí, entra o papel dos pais e cuidadores ao responderem tais curiosidades instigando-a mais e mais, preenchendo-os com respostas, criando então a cultura de curiosidade tão necessária a neuroplasticidade. Formatando tal cultura, se constrói nessa criança a vontade de aprender, a busca por mais conhecimentos, 
alterando e formando uma personalidade instigadora, investigativa, autodidata e curiosa. A vontade de ler e aprender relaciona-se a essa personalidade formatada pela cultura da curiosidade.

RELVAS (2009) explica que para compreender o mecanismo de aprender, é preciso conhecer o funcionamento do sistema nervoso central, o organizador dos nossos comportamentos, pois cada tipo de habilidade ou comportamento se relaciona a certas áreas do cérebro em particular, há áreas habilitadas a interpretar estímulos que levam à percepção visual e auditiva como o hipotálamo e a amígdala (presentes no sistema Límbico responsáveis pela memória e emoção), à compreensão e à capacidade linguística, à cognição, ao planejamento de ações futuras, inclusive dos movimentos.

A formatação da neuroplasticidade iniciada na infância leva à compreensão de que a memória pode ser trabalhada desde muito cedo. Uma criança inserida num meio familiar em que suas curiosidades são instigadas, sanadas e não desvalorizadas, terá mais possibilidades de memorizar o objeto do conhecimento, uma vez que tem contato com “"novo' e este fator pode determinar este 'novo' como aprendizado e, consequentemente, em memória por ser um cérebro mais adaptado". A memória tem três estágios: • Codificação que é o contato com as informações, o Armazenamento dessas informações e a Recuperação das informações. Para se armazenar na memória a atenção é necessária senão apresentará deficits. (ABREU, 2020, p. 2). A formação de memória de longo prazo, necessária no processo de aprendizagem da leitura, por exemplo, requer mudanças estruturais e funcionais nos neurônios, principalmente nas sinapses, e no aprendizado, novas sinapses são formadas e as antigas são fortalecidas.

OLIVIER (2010) afirma que a Aprendizagem, na visão das ciências cognitivas, ocorre em três estágios: subaprendizagem que é quando a pessoa entra em contato com o assunto, mas não prestou atenção e, portanto, não assimilou; aprendizagem simples, quando a pessoa entrou em contato com o assunto, prestou atenção, mas não memorizou; e a superaprendizagem ou aprendizagem ideal, que ocorre quando a pessoa entrou em contato com o assunto, prestou atenção, assimilou e memorizou. Nos dois primeiros casos, se faz necessário o acompanhamento interventivo para detectar onde há e qual é a falha existente, se são falhas psicológicas, orgânicas, ou falhas do sistema de ensinoaprendizagem - papel do mediador em Vygotsky (1998). 
Ensinar a uma pessoa uma habilidade nova implica maximizar potencial de funcionamento do cérebro, pois aprender exige planejar novos modos de solucionar desafios, atividades que estimulam diferentes áreas cerebrais a trabalhar com a máxima capacidade e eficiência. A aprendizagem só é formativa: "na medida em que opera transformações na constituição daquele que aprende” (RELVAS, 2009, p.26) e assim é possível dizer que ocorreu ativação de uma área cortical, determinada por um estímulo, provocando alterações em outras áreas em conexões intra-hemisféricas ou não.

A aquisição da leitura é processo complexo e necessita de todas as áreas cerebrais para ser desenvolvida. Aprendemos por três sistemas verbais: o auditivo (palavra falada), o visual (palavra lida) e o escrito, sendo que o auditivo é adquirido naturalmente, enquanto os demais sistemas são desenvolvidos. A linguagem pode ser compreendida em três aspectos: linguagem semântica - palavras faladas e escritas e seus significados; linguagem fonológica - som das palavras; e na sintaxe - regras gramaticais. A linguagem falada ou a fala se traduz em sons que partem da área cerebral chamada Broca e são dispostos em leitura ou em escrita.

Para a leitura, é necessária a participação da conexão existente entre o córtex visual (lobo occipital) onde são identificados os grafemas e a área de Wernick (lobo temporal), onde os símbolos gráficos da escrita são reconhecidos e compreendidos. Os sons são captados e levados até o córtex cerebral da área de Wernick, onde são decodificados e reconhecidos por meio da comparação com sons já memorizados anteriormente. A capacidade de decodificar os fonemas está ligada paralelamente à área de Broca (fonação) e a percepção verbal à área de Wernick, o que confirma que a aprendizagem da leitura e da escrita, invenções culturais necessitam de aprendizagem explicita e devem partir de estímulos sonoros e visuais para serem efetivadas. (Anexo 1)

A habilidade de decodificar é aprendida. "Se o decodificador é fraco, a compreensão de leitura será deficiente. Aprender a ler consiste essencialmente em adquirir as competências para decodificar”. (CAPOVILLA, 2005, p.22). "A leitura-escrita é um objeto cultural que foi criado e se desenvolveu a partir da readaptação de redes neurobiológicas destinadas a outras funções adaptativas de nossa espécie" (BENEDETTI, 2020, p. 111).

Paralelo ao sistema da fala, o sistema visual se estrutura e por volta dos seis anos de idade o sistema visual ventral (responsável pelo reconhecimento de letras) se encontra em 
intensa plasticidade, o que torna esse momento propício para o ensino da leitura, e que exige extensa reorganização neuronal (reciclagem neuronal) para se instalar nos circuitos visuais e linguísticos. O córtex occipitotemporal não se desenvolveu para aprender a ler, foram os sistemas de escrita que se adaptaram para serem reconhecidos por ele.

Figura 3 - A arquitetura cerebral do processamento da escrita

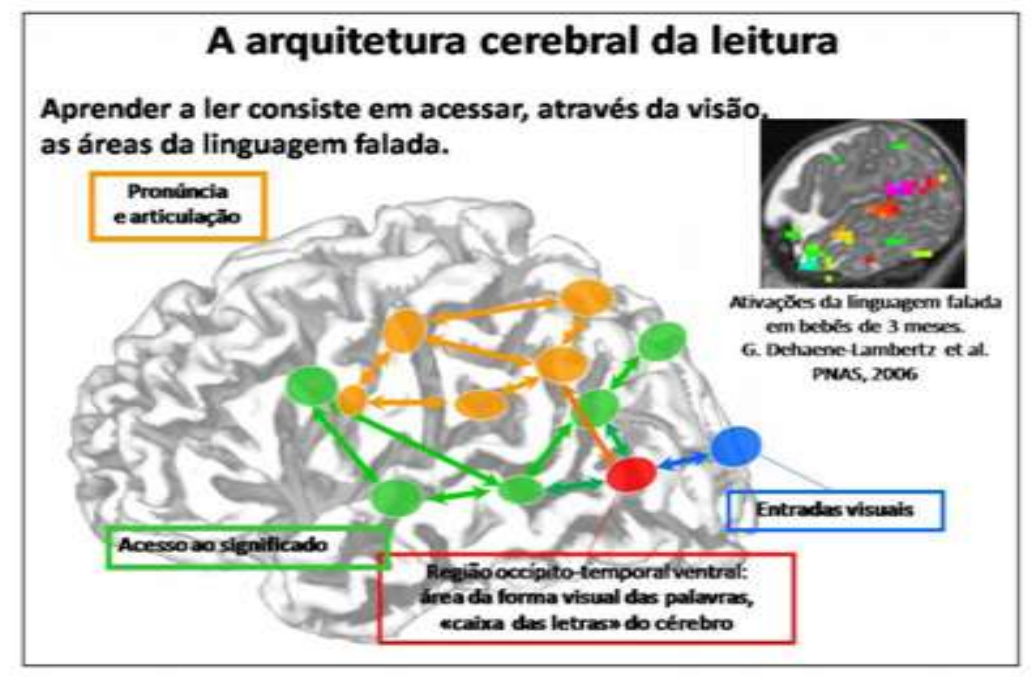

Fonte: Dehaene (2012)

Segundo DEHAENE (2012) não herdamos um órgão de leitura, e nem somos como barro maleáveis a todo tipo de aprendizagem, o que evidencia que o aprendizado se apoia no inato e a plasticidade cerebral tem certos limites, apesar de que, é ela que, em sua flexibilidade, reconverte parcialmente o nosso córtex visual para reconhecermos letras e palavras. O reconhecimento de palavras nos primatas não é global, "o objeto visual explode em miríades de pequenos fragmentos que nosso cérebro se esforça em recompor traço por traço e no caso da leitura, letra por letra” (BENEDETTI, 2020, p. 119).

A aprendizagem da leitura em DEHAENE (2012) passa por três fases na criança ou percurso cerebral e de forma universal (acontece no cérebro humano em qualquer lugar do planeta e para qualquer língua): a fase logográfica em que a criança registra ou identifica a imagem global de algumas palavras geralmente vistas com mais frequência como se as fotografasse dentro de um tratamento visual que se baseia no princípio de invariância das letras por meio das regiões visuais occipitais; a fase fonográfica em que a criança por meio do ensino-aprendizagem escolar aprende o princípio alfabético, acessando aos sons, aprende a decodificar os grafemas em classes de sons e a pronunciar por meio da região occipitotemporal ventral esquerda; e a fase ortográfica em que a 
criança, dentro de um treino e automatização da estratégia fonológica da leitura, passa a reconhecer a ortografia dos morfemas bem como o significado das palavras (áreas corticais semânticas), num processo em que os vários circuitos cerebrais, especialmente o córtex occipitotemporal esquerdo foi profundamente modificado, porque "Aprender a ler consiste, pois, em pôr em conexão as áreas visuais com as áreas da linguagem oral". (DEHAENE, 2012, P.78).

"à ativação e desenvolvimento de circuitos neurais em regiões específicas do cérebro, que desde a idade pré-escolar já se mostram presentes, localizando-se principalmente em áreas do hemisfério cerebral esquerdo" (ACADEMIA BRASILEIRA DE CIÊNCIAS Aprendizagem infantil, 2011, p.40).

Aprender as letras, os sons das letras, as invariâncias, fonemas, sílabas, letras, palavras e sentenças, não significa que o ensino da compreensão deva ser deixado de lado ou para ato posterior, muito pelo contrário, os dois processos devem ser atrelados e caminharem juntos. Ler ajuda o leitor a ampliar a compreensão, pois, a leitura sempre implica tanto a capacidade de reconhecer quanto de compreender o significado do que se lê. Para entender um texto escrito, a pessoa aprende ler, torna-se capaz de ler e usa tal capacidade para ampliar a compreensão aprendendo cada vez mais. "Aprender a ler consiste essencialmente em adquirir as competências para decodificar." (GT: ALFABETIZAÇÃO INFANTIL: os novos caminhos relatório final, 2007, p.27) e o documento continua:

"A essência de aprender a ler consiste em traduzir letras (impressas, escritas) em sons que fazem sentido. [...] aprender a fazer a decodificação fonológica (isto é, converter os sons em letras para escrever e letras em sons para ler). [...] o objetivo da leitura é permitir ao leitor compreender, interpretar e modificar o texto dialogando com ele.” (p.27) “É um fato científico bem estabelecido que aprender a ler requer: compreender o princípio alfabético, aprender as correspondências entre grafemas e fonemas, segmentar sequencias ortográficas de palavras escritas em grafemas, segmentar sequencias fonológicas de palavras faladas em fonemas e usar regras de 
correspondência grafema-fonema para decodificar informação." (p.28)

Ler é como uma conquista do aprendiz: o processo de alfabetização seve para ajudar a criança a descobrir o princípio fundamental, o princípio alfabético subjacente ao código alfabético bem como todas as habilidades que são necessárias ao desenvolvimento do leitor fluente: processamento fonológico, a manipulação morfossintática da linguagem, a memória de trabalho e do pensamento lógico, memória fonológica, vocabulário, consciência fonológica (especialmente a fonêmica) e sequenciação. O cérebro das crianças extrai os segmentos da fala, explorando suas regularidades e regras fonológicas e esse aprendizado é implícito e espontâneo, já a aprendizagem da leitura e da escrita exige ensino sistemático e explícito.

\subsection{Métodos de Ensino da Leitura}

Considerando a evolução científica constante e rápida, e principalmente na área da Educação em especial nas bases da alfabetização dentro da neurociência, as evidências científicas obrigam os pesquisadores a reverem e reformularem suas teorias e hipóteses e isso em qualquer área do conhecimento. A maior questão é: Por que o Brasil e seu sistema educacional ainda insistem em permanecer aquém das descobertas científicas sobre como o cérebro humano aprende ler, envolto em políticas e práticas de alfabetização, cujos métodos são oriundos de países desenvolvidos, porém que já superaram e reformularam seus métodos de alfabetização? Não é mais possível que áreas como a educação, a psicologia, a pedagogia, a fonoaudiologia e outras permaneçam atrasadas sob o ponto de vista neurobiológico de como o cérebro humano aprende ler. Os resultados têm sido desastrosos.

O ensino da leitura tem sido desenvolvido por dois caminhos ou abordagens: o global e o analítico denominado fônico. Esse último se dá pelo ensino do princípio alfabético, pois como considera que o aprendizado da leitura não é natural e espontâneo, vê a necessidade da aprendizagem formal do alfabeto através do ensino sistemático e explícito da consciência fonológica. O método global baseia-se no reconhecimento de palavras inteiras como uma unidade da leitura e do contexto da criança. O ensino do som das letras não ocorre de modo explícito. O relatório GT: ALFABETIZAÇÃO INFANTIL: os novos caminhos relatório final (2007) traz a seguinte consideração com base em experiências de outros países de primeiro mundo: 
"as práticas de ensino recomendadas pelos PCNS não representam as melhores técnicas e prática, reconhecidas mundialmente para a alfabetização de crianças; a concepção de alfabetização esposada e adotada pela maioria das Secretarias de Educação no Brasil não é compartilhada pelos governos dos países industrializados em que predominam línguas de base alfabética." (p.146)

Sem a prepotência de subestimar a importância dos documentos que nortearam a educação brasileira e principalmente a alfabetização, é possível perceber que nos Parâmetros Curriculares Nacionais (PCNS, 1998) e na BNCC (2017) a aprendizagem da leitura não pode iniciar com letras, sílabas e palavras ou sentenças fora de contexto, confundindo-se o objetivo (é ensinar o aluno a produzir e interpretar textos) com o processo (aprender a ler) de alfabetização, ignorando completamente as descobertas da neurociência que afirma, através de todo o estudo e mapeamento cerebral, que nosso sentido visual capta a imagem e essa se explode em pequenos fragmentos que o nosso cérebro se esforça para recompor traço por traço, letra por letra, além do que confunde ler com compreender. A abordagem de ensino global das palavras exige demasiadamente da memória da criança, pois não lhe foi ensinado o domínio do código alfabético para decifração. O cérebro é obrigado a utilizar vias neuronais que não são adequadas para processar a leitura (a ativação cerebral se dá no hemisfério direito na abordagem global). E, mesmo que seja um progresso lento, a leitura a partir da decodificação grafema-fonema lhe permite mais segurança, menos probabilidade de errar na escrita quando for adulto bem como o domínio do código alfabético, faz com que a criança leia palavras novas ou não.

Lemos para compreender, pois esse é o propósito da leitura e não deve ser ignorado por nenhum método. Uma pessoa consegue compreender sem ler e ler sem compreender. "Ler é diferente de aprender a ler. O processo de aprender a ler não pode ser confundido com o propósito da leitura”. (CAPOVILLA, 2005, p.20). O propósito de aprender a ler para compreender prescinde de aprender o ato de ler e escrever, e um processo não impede o outro.

"Os estudos de imagem funcional e neurofisiológicos tem demonstrado que durante o aprendizado da leitura de acordo com o modelo fonológico, o ensino da correspondência fonema-grafema 
implica uma maior ativação dos giros temporal superior angular e supra marginal do hemisfério esquerdo que é a denominada via indireta." (ACADEMIA BRASILEIRA DE CIÊNCIAS aprendizagem infantil, 2011, p.67)

Diversos países demonstrando grande preocupação com seus métodos de alfabetização e questões de ordem educacional. Todos os estudos neurocientíficos em relação à leitura reforçam a importância da estimulação da capacidade de decodificação fonológica no início da alfabetização (05 aos 07 anos), independente da abordagem e método utilizado, pois tal atraso pode implicar na perda do melhor momento para o desenvolvimento dessa capacidade, passado esse momento (chamado período crítico), as técnicas seriam em torno de intervenção e reabilitação para efetivação do aprendizado da leitura. O processo fônico, portanto, é benéfico visto que se corresponde ao processo neurobiológico.

\subsection{Políticas de Alfabetização}

Ao analisarmos historicamente, percebemos que as políticas e práticas de alfabetização no Brasil se mantiveram firmes e arraigadas às concepções sociais de educação e, portanto, sob um único viés de compreensão e aplicabilidade. Para tanto se faz necessário que as políticas de alfabetização acompanhem os avanços neurocientíficos em benefício público como preconizado nos objetivos da OECD (Organization for Economic Cooperation and Development):

"fundamentar e definir os requisitos para uma colaboração entre a ciência da educação e a investigação do cérebro" e em "promover a aproximação entre os políticos de educação e os investigadores do cérebro, bem como apresentar fatos de investigação que possamos (e que devíamos e devemos) transpor para as práticas, se quisermos tornar o sistema educativo mais eficiente". (ACADEMIA BRASILEIRA DE CIÊNCIAS - aprendizagem infantil, 2011, p.69)

Em 2003, a partir do Programa Brasil Alfabetizado, o "GT: ALFABETIZAÇÃO INFANTIL: os novos caminhos" criou um relatório final que foi apresentado pela Comissão de Educação e Cultura na Câmara dos Deputados no governo do Presidente Luís Inácio Lula da Silva, trouxe uma extensa e embasada discussão sobre as descobertas neurocientíficas da aprendizagem da leitura, no Seminário $O$ poder Legislativo e a Alfabetização Infantil: os novos caminhos, realizados em 15 de setembro de 2003, que se 
transformou em um relatório documental em 2007. Em 2004, o Comitê Cearense para a Eliminação do Analfabetismo Escolar da Assembleia Legislativa do Estado do Ceará, elaborou um relatório final Educação de Qualidade Começando pelo Começo que apontou para a alfabetização os mesmos componentes essenciais identificados pelo National Reading Panel dando origem ao Programa Alfabetização na Idade Certa (PAIC) do estado do Ceará. (PNA, 2019, p.17).

O documento, em comparação com as orientações gerais, documentos nacionais e programas de alfabetização de outros países com o Brasil constatou que: as diretrizes de programas e currículos são baseadas em critérios científicos e não filosóficos como no Brasil, pois o critério filosófico é de competência da escola como instituição e consta em seu projeto político pedagógico, o PPP; porém, as diretrizes são concretas abrangendo competências e habilidades a serem ensinadas no ciclo de alfabetização; as instruções para o ensino estruturado e sequencial da alfabetização é detalhado e diretivo; os conteúdos a serem ensinados no ciclo de alfabetização devem ser relacionados às competências necessárias para aprender a ler, voltados para a decodificação, o domínio do código alfabético, a consciência fonológica, fluência e compreensão, diferentemente dos programas e políticas de alfabetização no Brasil.

Em 2017, foi promulgada a BNCC e em 2018 foi criado o programa Mais Alfabetização. Assim, considerando a alfabetização, a BNCC mantém os principais pressupostos contidos nos PCNS, porém apresenta mudanças que já podem ser visíveis na perspectiva de que a apropriação do sistema alfabético de escrita tem especificidades e deve ser colocado como foco principal da ação pedagógica nos anos iniciais, podendo vislumbrar uma ligação entre o final da educação infantil e o início do ensino fundamental: o ciclo da alfabetização. Apesar de não perder o foco do uso social da língua e das hipóteses de escrita como visto nos PCNS, a Base demonstra certa abertura para o trabalho explícito com o sistema alfabético e com a consciência fonológica e propõe habilidades e competências ora na aquisição da notação alfabética, ora na imersão do texto em seu contexto social. Tais aspectos, não devem ser dissociados.

Em 2019, foi criada a PNA - Política Nacional De Alfabetização tentou resgatar, a base científica sobre como o cérebro humano aprende a ler, via Decreto 9.765 de 11 de abril de 2019. Diversos grupos da sociedade letrada participaram da construção desse documento inserindo no Brasil os fundamentos das ciências cognitivas para obtenção de 
práticas de alfabetização mais eficazes, baseados em evidências científicas e de experiências exitosas no Brasil e no mundo. Divide-se em literacia, numeracia e alfabetização: a literacia consiste no ensino e na aprendizagem de habilidades de leitura e escrita independente do sistema de escrita utilizado avançando para a aplicabilidade (compreensão autônoma e produção do conhecimento) e é dividida em literacia básica, intermediária e disciplinar, (UNESCO, 2006) e alfabetização é o ensino das habilidades de leitura e escrita em um sistema alfabético. (PNA p.18).

Outro programa criado a partir da PNA é o Tempo de Aprender, cujo propósito é enfrentar as principais causas das deficiências da alfabetização no país e destinado aos últimos anos pré-escola e ao $1^{\circ}$ e $2^{\circ}$ ano do ensino fundamental das redes públicas estaduais, municipais e distrital, oferecendo Apoio pedagógico para a alfabetização, Formação continuada de profissionais da alfabetização com ênfase nas competências e habilidades da BNCC e ensino explícito, direto e sistemático a partir da consciência fonológica e apreensão do código alfabético cujos módulos são: Aprendendo a ouvir, Conhecimento alfabético, Fluência, Vocabulário, Compreensão, Produção de escrita, Avaliação bem como Aprimoramento das avaliações da alfabetização e Valorização dos profissionais de alfabetização. Foi lançado, em 2020, o Curso ABC - Alfabetização Baseada em Evidências, trazendo as perspectivas teóricas da temática a partir do $\operatorname{RENABE}^{8}$.

\section{METODOLOGIA}

Esse artigo utilizou como estratégia de pesquisa a pesquisa bibliográfica, cujas fontes de pesquisa foram os relatórios técnicos e artigos, bem a pesquisa em livros de autores renomados, somados a coleta de dados por meio de pesquisa realizada junto aos bancos de dados do MEC e outros sites ligados à Educação.

Esta pesquisa tem o caráter exploratório e descritivo na medida em que tenta responder algumas perguntas, compreender alguns dados coletados, aprofundar estudos, descrever a temática e explicar os conceitos a serem apresentados sobre a alfabetização aprendizagem da leitura baseada nas Ciências Cognitivas da Leitura, interconectada, portanto, com a neurociência educacional, psicologia cognitiva e pedagogia. Seu caráter exploratório advém da pergunta se há ou houve no país pesquisas e políticas de alfabetização baseada em neurociência, decorrendo da busca por relatórios ou programas

\footnotetext{
${ }^{8}$ Relatório Nacional de Alfabetização Baseada em Evidências contém os trabalhos de pesquisas de inúmeros teóricos envolvidos na elaboração da PNA, brasileiros e estrangeiros.
} 
de alfabetização que condizem com o referencial teórico e quais foram os resultados em alfabetização no país nos últimos anos.

A finalidade desse trabalho é de suscitar o aprofundamento do estudo sobre o referencial teórico para desenvolver trabalhos científicos e aplicabilidade no contexto da sala de aula, tendo em vista a quase escassez de materiais de pesquisa nessa temática e de materiais didáticos e pedagógicos que sejam devidamente elaborados para o trabalho de base na alfabetização e no ensino da língua materna tendo como pressuposto a Neurociência Cognitiva/Educacional.

\section{RESULTADOS}

Compreendendo que o cérebro humano tem múltiplas eficiências, como cérebro individual, social, motor, afetivo-emocional, criativo, inventivo e genial, bem como conhecendo como ele se comporta para promover a aprendizagem, o professor terá outra perspectiva de prática educativa, não somente pela necessidade de mudança pura e simples, mas pelo conhecimento de como fazer o aluno aprender ou de como atuar diante das desordens do aprender. A mudança ocorrerá consequentemente, na concepção de que o foco será na aprendizagem e não somente no processo de ensino.

Se esse profissional está seguro quanto ao seu repertório da aprendizagem da leitura baseada em evidências científicas, inevitavelmente, ele mudará ou adequará suas práticas de ensino. Perceberá que a aula puramente expositiva, sem a preocupação consciente com os conhecimentos prévios e estímulos motivadores da criança, sem a preocupação do fazer junto (mediação didática e mediação cognitiva pela instrução direta), sem a inovação para tratar de um mesmo conteúdo para que atinja a todos os tipos de inteligência, possivelmente fracassará em seus objetivos e no processo de ensino. Há que se criar "ciclos de educação individualizada com base em todo o potencial tecnológico", visto que a Educação deve ser singular e não plural, pois, "o aluno, o ser que está diante de nós deve ser visto nas suas particularidades, deve ser motivado a desenvolver as suas capacidades, as áreas de seu interesse e onde é particularmente notável. O ensino deve ser feito com ritmo próprio explorando o melhor de cada um" (ABREU, 2020). A instrução direta parte do princípio que todos os alunos podem aprender desde que recebam as instruções motivadoras, estimuladoras (estimulação planejada) e bem adequadas/apropriadas aos tipos de inteligências apresentadas na sala de aula. 
Em termos de políticas públicas específicas para a alfabetização se faz necessário, basearse em critérios e métodos científicos, definir claramente o que seja e como seja alfabetização, prover materiais e formação para os professores, avaliar os resultados sistematicamente, ampliar debates e foros para a produção científica, e no âmbito da sala de aula, ampliar o uso do ensino sistemático, explicito e direto, adequar o tempo da instrução direta, usar sistematicamente a abordagem fônica para o ensino da leitura, utilizar instrumentos de diagnóstico do processo, promover a literacia familiar, intermediária e avançada, bem como aprimorar e aperfeiçoar questões relacionadas ao docente e à gestão da escola em todo o território nacional.

\section{CONSIDERAÇÕES FINAIS}

Busca-se, portanto, por meio dessa proposta, incentivar estudos posteriores no que se refere a avaliar a efetividade dos métodos de alfabetização desenvolvidos em sala de aula por todo o país bem como avaliar os resultados, seja em contextos experimentais de laboratórios, seja em estudos de campo envolvendo professores e suas salas de aula, tomando como exemplo as muitas revisões da literatura que abordam esse tema pelo viés da neurociência em outros países, e que utilizaram complexos modelos estatísticos para discutir os resultados em alfabetização.

Urge a necessidade de produção de material didático - pedagógico e pesquisa cientifica com base em neurociência sobre os elementos de que a Ciência Cognitiva da Leitura expõe no processo da alfabetização: a consciência fonológica, a consciência fonêmica, a decodificação do sistema e código alfabético, a fluência, a ampliação do vocabulário, a compreensão e a produção da escrita. A Ciência Cognitiva da Leitura opta pela instrução fônica ou abordagem fônica, comprovadamente como a mais eficaz para alfabetizar, apesar de ser o mais criticado.

Visualizam-se avanços, nas políticas públicas de educação vigentes como a BNCC e a PNA, pois, a partir delas podemos vislumbrar o alcance das metas 5 e 9 propostas no Plano Nacional de Educação tendo em vista que Alfabetização é um instrumento de superação de vulnerabilidade social. Daí decorre a necessidade enquanto sistema educacional, de ampliação dos estudos na área para responder essas e outras questões a fim de criar programas de alfabetização eficazes, preventivos e corretivos, pois, isso é o mínimo que podemos garantir às crianças da sociedade brasileira. 


\section{REFERÊNCIAS}

ABREU. F. Educação é individual e não plural. EDUCAGERAL, São Paulo, 11 de junho de 2020. https://educageral.com.br/geral/educacao-e-individual-e-naoplural/ Acesso em 12/09/2021.

Técnicas para uma melhor memorização: levando em consideração as nuances da personalidade. Brazilian Journal. of Development., Curitiba, v. 6, n.12, p. $103674-103704$ dec. 2020.

Relação entre a fadiga, dependência de dopamina com as disfunções neuronais. Brazilian Journal. of Development., Curitiba, v. 6, n. 11, p. p. 85183-85194, nov. 2020.

ACADEMIA BRASILEIRA DE CIÊNCIAS. Aprendizagem infantil: uma abordagem da neurociência, economia e psicologia cognitiva. Rio de Janeiro: Academia Brasileira de Ciências, 2011.

BENEDETTI. K. S. A falácia socioconstrutivista: porque os alunos brasileiros deixaram de aprender a ler e a escrever. São Paulo: CEDET, 1ª edição, 2020.

BRASIL. Lei de Diretrizes e Bases da Educação Nacional. Lei número 9394, 20 de dezembro de 1996.

. Congresso Nacional. Câmara dos Deputados. Comissão de Educação e Cultura.

Relatório Final do Grupo de Trabalho Alfabetização Infantil: os novos caminhos. 1 ed. Brasília: [s.n.], 2003.

. Congresso Nacional. Câmara dos Deputados. Comissão de Educação e Cultura. Relatório Final do Grupo de Trabalho Alfabetização Infantil: os novos caminhos. 2. ed. Brasília: [s.n.], 2007.

1995. Parâmetros Curriculares Nacionais - Documento Introdutório. Versão Preliminar. Brasília: MEC/SEF, novembro.

1997 a. Parâmetros Curriculares Nacionais (1ª a $4^{\mathrm{a}}$ séries). Brasília: MEC/SEF, 10 volumes.

Ministério Da Educação. Base Nacional Comum Curricular. Brasília: [s.n.], 2018.

. Ministério da Educação. Secretaria de Alfabetização. Conta pra Mim: Guia de Literacia Familiar. - Brasília: MEC, SEALF, 2019. 
Ministério da Educação. Secretaria de Alfabetização. PNA: Política Nacional de Alfabetização. - Brasília: MEC, SEALF, 2019.

Lei $n^{\circ} 13.005$, de 25 de junho de 2014. Aprova o Plano Nacional de Educação

- PNE e dá outras providências. Diário Oficial da União, seção 1, 26 jun. 2014.

CAPOVILLA. F.C. Os novos caminhos da alfabetização infantil. São Paulo: Memnon edições científicas, $2^{\text {a }}$ edição, 2005.

DEHAENE. S. A aprendizagem da leitura modifica as redes corticais da visão e da linguagem verbal. Letras de Hoje, Porto Alegre, v. 48, n. 1, p. 148-152, jan/mar. 2013.

DEHAENE, S. Os neurônios da leitura. Porto Alegre: Penso, 2012.

GARDNER, H. Inteligências Múltiplas: a teoria na prática. Trad. Maria Adriana Veríssimo Veronese. Porto Alegre: Artes Médicas, 1995.

A nova Ciência da Mente: uma história da revolução cognitiva. Trad. Cláudia Malbergier Caon; São Paulo: ed. Universidade de São Paulo, 2ª ed. 1996.

INEP. Avaliação nacional da alfabetização (ANA): documento básico. Brasília: Inep, 2013.

. Avaliação nacional da alfabetização: relatório 2013-2014: volume 1: da concepção à realização. Brasília: Inep, 2015a.

. Avaliação nacional da alfabetização: relatório 2013- 2014: volume 2: análise dos resultados. Brasília: Inep, 2015b.

. Plano Nacional de Educação PNE 2014-2024: Linha de base. Brasília: Inep, 2015c.

. Brasil no PISA 2015: Análises e reflexões sobre o desempenho dos estudantes brasileiros. Brasília: Inep/MEC, 2016 a.

. Relatório do 10 ciclo de monitoramento das metas do PNE: biênio 20162014. Brasília: Inep, 2016 b.

. Relatório do 20 ciclo de monitoramento das metas do Plano Nacional de Educação - 2018. Brasília: Inep, 2018 a.

MORA, F. Como funciona o cérebro. Porto Alegre, Artmed, 2004.

OLIVIER. L. de. Distúrbios de aprendizagem e de comportamento. Rio de Janeiro, Wak Ed. $5^{\text {a }}$ edição, 2010. 
PIAZZI. P. Ensinando inteligência: manual de instruções do cérebro de seu aluno. São Paulo, $2^{a}$ ed. Aleph, 2014, coleção Neuroimagem, vol.3.

RELVAS. M. P. Neurociência e Educação: potencialidades dos gêneros humanos na sala de aula - relação entre o cérebro masculino e feminino na aprendizagem. Rio de Janeiro: Wak Ed., 2009.

Neurociência e transtornos de aprendizagem: as múltiplas eficiências para uma educação inclusiva. Rio de Janeiro: Wak Ed., $3^{\text {a }}$ edição, 2009

SNOWLING \& HOLME. M. C. A Ciência da leitura. Porto Alegre: Penso, 2013, dados eletrônicos.

VYGOTSKY. L.S. A Formação Social da Mente. 6. ed. São Paulo: Martins Fontes, 1998. 


\section{ANEXO 1-}

Áreas de Broca e Wernicke na Aprendizagem da Leitura

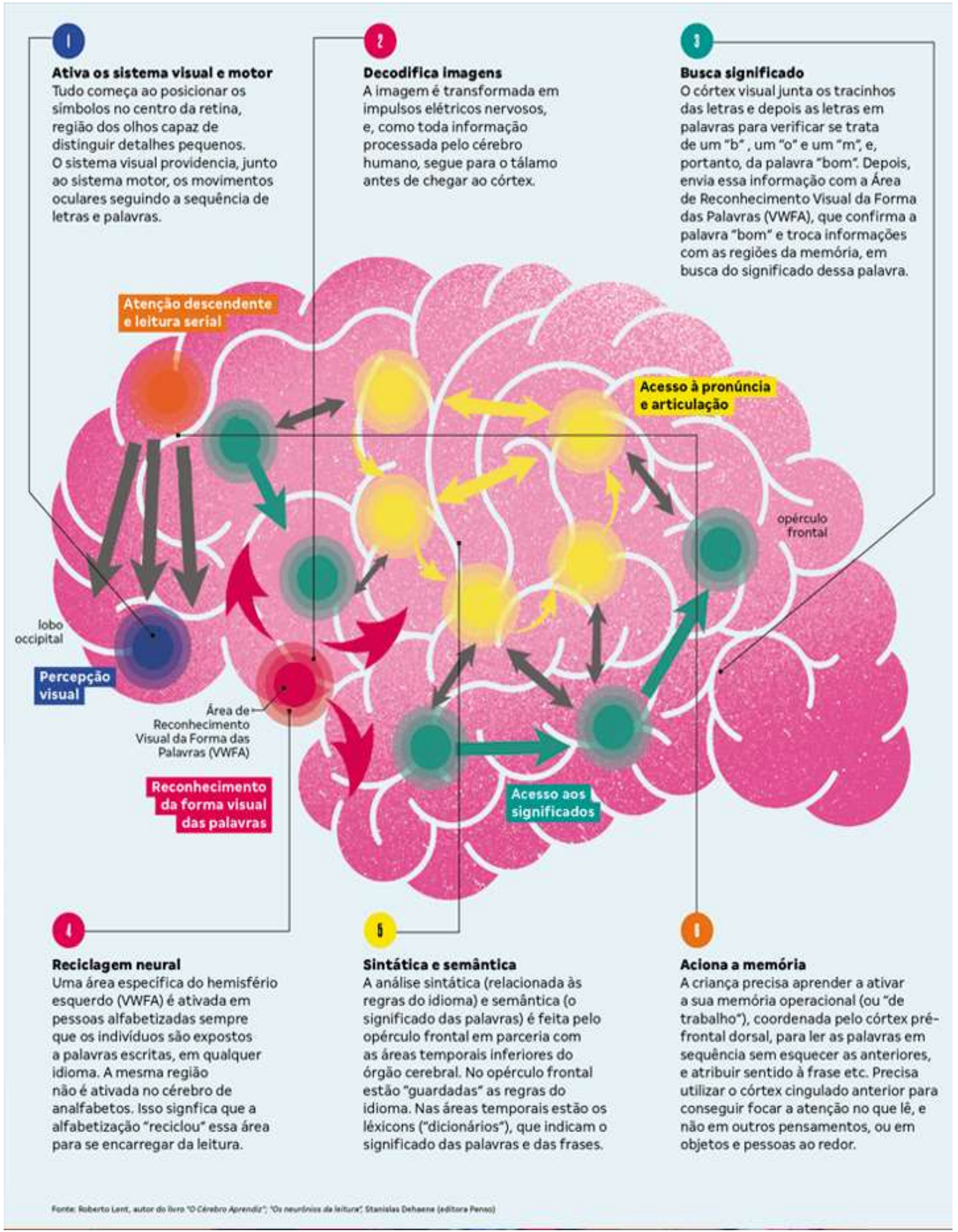

https://novaescola.org.br/conteudo/16062/como-a-neurociencia-pode-ajudar-a-educacao Acesso em 10/09/2021. 